\title{
Effective Control of Bioelectricity Generation from a Microbial Fuel Cell by Logical Combinations of $\mathrm{pH}$ and Temperature
}

\author{
Jiahuan Tang, ${ }^{1,2}$ Ting Liu, ${ }^{3}$ Yong Yuan, ${ }^{2}$ and Li Zhuang ${ }^{2}$ \\ ${ }^{1}$ Guangzhou Institute of Geochemistry, Chinese Academy of Sciences, Guangzhou 510640, China \\ ${ }^{2}$ Guangdong Institute of Eco-Environmental and Soil Sciences, Guangzhou 510650, China \\ ${ }^{3}$ College of Bioscience and Biotechnology, Hunan Agricultural University, Changsha 410128, China
}

Correspondence should be addressed to Yong Yuan; yuanyong@soil.gd.cn

Received 27 December 2013; Accepted 27 January 2014; Published 11 March 2014

Academic Editors: B. Cao, Y.-C. Yong, and S.-G. Zhou

Copyright (C) 2014 Jiahuan Tang et al. This is an open access article distributed under the Creative Commons Attribution License, which permits unrestricted use, distribution, and reproduction in any medium, provided the original work is properly cited.

\begin{abstract}
In this study, a microbial fuel cell (MFC) with switchable power release is designed, which can be logically controlled by combinations of the most physiologically important parameters such as "temperature" and "pH." Changes in voltage output in response to temperature and $\mathrm{pH}$ changes were significant in which voltage output decreased sharply when temperature was lowered from $30^{\circ} \mathrm{C}$ to $10^{\circ} \mathrm{C}$ or $\mathrm{pH}$ was decreased from 7.0 to 5.0. The switchability of the MFC comes from the microbial anode whose activity is affected by the combined medium temperature and $\mathrm{pH}$. Changes in temperature and $\mathrm{pH}$ cause reversible activation-inactivation of the bioanode, thus affecting the activity of the entire MFC. With temperature and $\mathrm{pH}$ as input signals, an AND logic operation is constructed for the MFC whose power density is controlled. The developed system has the potential to meet the requirement of power supplies producing electrical power on-demand for self-powered biosensors or biomedical devices.
\end{abstract}

\section{Introduction}

Microbial fuel cells (MFCs) are energy-producing devices that can directly generate electric energy from the oxidation of various organic matters with the aid of microbes. Since MFCs are capable of generating electricity in an environmentally friendly manner, they have attracted a great deal of research attention over the past decades [1-3]. One of the potentially important applications of MFCs is powering sensors or biomedical devices. Tender et al. [4] and Zhang et al. [5] succeeded in powering temperature sensors using MFCs in natural environments. Siu et al. proposed that MFCs were capable of powering biological microelectromechanical systems (bioMEMS) [6]. Recently, major research concerns have been raised about increasing energy output of MFCs as power supplies. In the case of powering sensors or biomedical devices, switchable or tunable electrical power release would be a great advantage for their application, given their adaptive behavior and power production on demand.
Enzyme-based biofuel cells with self-regulating power release have been intensively studied using switchable biocatalytic electrodes controlled by physical or biochemical signals [7]. In such devices, the biocatalytic electrodes were usually modified with signal-responsive materials that were sensitive to triggering actions to make the electrodes electrochemically active or inactive. For instance, Katz and Willner reported that the power production of a biofuel cell was switched ON and OFF by integrating a biocatalyst with a copper polyacrylic acid matrix of controllable conductivity properties [8]. Amir et al. regulated the power release of a biofuel cell using a $\mathrm{pH}$-sensitive redox polymer [9]. The polymer allowed switching between redox active and inactive states by $\mathrm{pH}$ induced swelling and shrinking processes, respectively. Other biofuel cell systems with controllable power release were also realized by being integrated with enzyme- or immune-based systems, enabling the switchable and tunable functions of the biofuel cells $[10,11]$. Although promising progress has 
been achieved for enzyme-based biofuel cells, their longterm stability and scalability need to be improved, and the complicated manufacturing process of enzyme electrodes severely limit their practical application. MFCs are promising alternatives to enzyme-biofuel cells due to the use of whole bacterial cells which are stable for a long time, scalable, selfattachable on the electrodes as catalysts. Microbial electrodes or assembled MFCs are capable of switching the electron transfer process or self-regulating power release as well. Yuan et al. developed a switchable microbial electrode with electrical signal output by controlling the presence of acetate and oxygen [12]. For the first time, Li et al. integrated an MFC with an AND logic gate to self-regulate power release [13]. However, a Pseudomonas aeruginosa lasI/rhlI double mutant was employed as the biocatalyst and two quorumsensing signaling molecules were used as input signals in their study, involving rather complex genetic operations and slow switching speed.

In this study, we demonstrated a simple method to regulate the electricity generation from an MFC by controlling the most important physiological parameters $(\mathrm{pH}$ and temperature), where a sharp thermal and $\mathrm{pH}$ response of the microbial anode of the MFC has been logically designed. The bioanode could switch between electrochemically active and inactive states in response to the operation environment, resulting in the "smart" bioelectricity generation from the assembled MFC. The present paper extends the fundamental research activity in bioelectricity generation of MFCs with switchable or tunable functions.

\section{Materials and Methods}

2.1. MFC Construction and Startup. MFCs with an inner volume of $12 \mathrm{~mL}$ were constructed as previously reported with minor modification on the anodes [14]. A cylindrical MFC chamber with a length of $1.7 \mathrm{~cm}$ and a diameter of $3.0 \mathrm{~cm}$ in the cathode side and $1.8 \mathrm{~cm}$ in the anode side was made of plexiglass, resulting in a surface area of $7.0 \mathrm{~cm}^{2}$ for the cathode and $2.5 \mathrm{~cm}^{2}$ for the anode. The cathode was prepared with a $30 \%$ wet-proof carbon cloth (type B, E-TEK, USA) with four layers of polytetrafluoroethylene (PTFE) (PTFE30, DuPont, USA) coating. Pt/C (20\% Pt, E-TEK, USA) was used as the cathode catalyst with a Pt loading of $0.5 \mathrm{mg} \mathrm{cm}^{-2}$. Carbon cloth (type A, E-TEK, USA) was used as the anode electrode. Reactors were inoculated with $2 \mathrm{~mL}$ activated sludge (Liede Wastewater Treatment Plant, Guangzhou, China) in $10 \mathrm{~mL}$ sodium acetate $\left(1000 \mathrm{mg} \mathrm{L}^{-1}\right)$ culture medium. Besides sodium acetate, the culture medium contained $\mathrm{KH}_{2} \mathrm{PO}_{4}$ (13.6 $\left.\mathrm{g} \mathrm{L}^{-1}\right), \mathrm{NaOH}\left(2.32 \mathrm{~g} \mathrm{~L}^{-1}\right), \mathrm{NH}_{4} \mathrm{Cl}\left(0.31 \mathrm{~g} \mathrm{~L}^{-1}\right), \mathrm{NaCl}$ $\left(1.0 \mathrm{~g} \mathrm{~L}^{-1}\right)$, a vitamin stock solution $\left(12.5 \mathrm{~mL} \mathrm{~L}^{-1}\right)$, and a mineral stock solution $\left(12.5 \mathrm{~mL} \mathrm{~L}^{-1}\right)$. Power density curves were obtained by changing the circuit resistor from $50 \Omega$ to $5000 \Omega$. All tests were conducted in duplicate, and mean values were presented.

2.2. UV-Vis Spectroscopy. Prior to spectroscopy measurements, pure Geobacter strain was cultured and harvested. Geobacter sulfurreducens strain PCA (ATCC 51573) was cultured as previously reported at $30^{\circ} \mathrm{C}$ using a vitamin-free anaerobic medium [15]. Acetate was provided as an electron donor at $30 \mathrm{mM}$ and $40 \mathrm{mM}$ fumarate as electron acceptor. UV-Vis spectra of intact cells of PCA were recorded in diffused transmission mode with bacterial cells suspended in a bicarbonate buffer [16]. The cell suspension was injected into a cuvette, and it was mounted in front of an integrating sphere to measure the diffuse transmission light. Full reduction of the cells was achieved by adding sodium dithionite $(25 \mathrm{mM})$ to the cell suspension and oxidation of the whole cell was obtained by purging oxygen into the cell suspension for $10 \mathrm{~min}$ before measuring.

2.3. Electrochemical Measurements. Electrochemical characterization of the mixed-culture anode was carried out with cyclic voltammetry (CV) using a CHI660D workstation (Shanghai CH Instrument Company, China) with a threeelectrode system, where the biofilm-attached anode served as the working electrode, saturated calomel electrode (SCE) as the reference electrode, and the cathode as the counter electrode. A phosphate buffer ( $0.05 \mathrm{M}$; no culture medium) was used as the electrolyte under no-turnover conditions. $\mathrm{CV}$ under turnover conditions was measured when the voltage output of the MFC at $1000 \Omega$ was maximized and stabilized.

2.4. Scanning Electron Microscopy. Prior to scanning electron microscopy (SEM) measurements, the mixed-culture biofilm-attached electrode was first fixed in a $2.5 \%$ glutaraldehyde solution for $1 \mathrm{~h}$, then in a series of ethanol dehydration solution (i.e., 25\%, 50\%, 75\%, and 100\% v/v EtOH; $0.5 \mathrm{~h}$ each treatment), and after that, dried at the $\mathrm{CO}_{2}$-critical point for $3 \mathrm{~h}$. The resultant specimen was coated with gold using a coating device (Emitech K550X; UK) and observed under a SEM (JEOL, JSM-6330F; Japan) at $20 \mathrm{kV}$.

\section{Results and Discussion}

3.1. Responses of Voltage Output to $\mathrm{pH}$ and Temperature Variations. An MFC can be a very robust device when it is subjected to short-term changes of operating parameters such as temperature and $\mathrm{pH}$. To probe the response of MFC performance to these parameters, an MFC inoculated with a mixed consortium was constructed. The structure and morphology of the self-assembled mixed-culture bioanode were characterized with SEM (Figure 1(a)). Nearly the entire surface of the solid carbon cloth electrode was covered with rod-shaped bacterial cells. Changes in voltage output in response to temperature and $\mathrm{pH}$ changes were shown in Figure 1(b). Voltage output decreased sharply when temperature was lowered from $30^{\circ} \mathrm{C}$ to $10^{\circ} \mathrm{C}$ or $\mathrm{pH}$ was decreased from 7.0 to 5.0. Previous studies reported similar changes of the voltage output in response to temperature and $\mathrm{pH}$ changes $[14,17,18]$. Gonzalez del Campo et al. pointed out that temperature could affect MFC voltage output by influencing microbial metabolism, membrane permeability, and ohmic resistance of the electrolyte [17]. In the case of effects of medium $\mathrm{pH}$ on the power generation of an MFC, it was found that acidification of the anode affected 


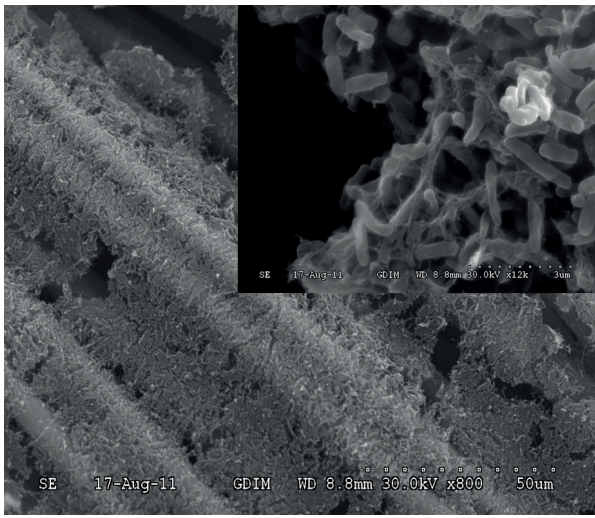

(a)

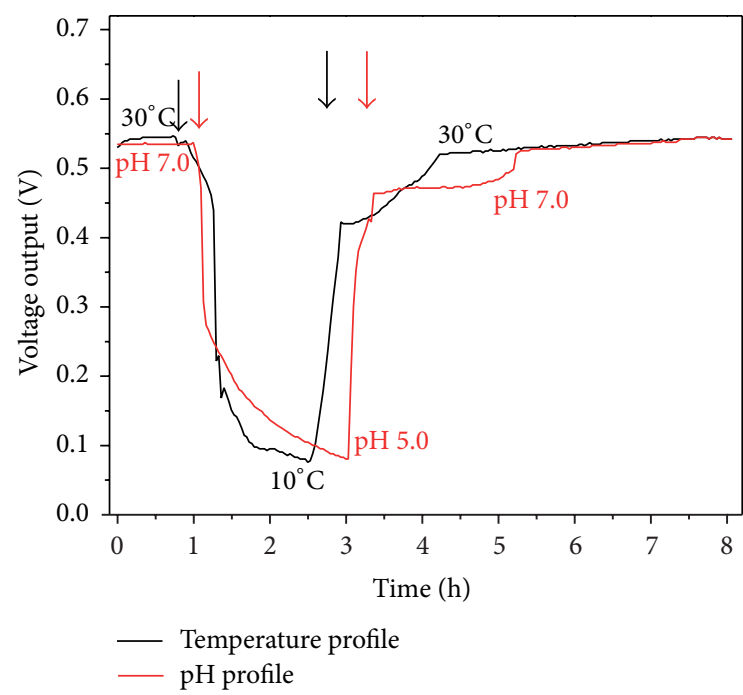

(b)

FIGURE 1: (a) SEM images of the anode biofilm (inset: high resolution image); (b) voltage output versus time curves with the variation of temperature and $\mathrm{pH}$.

electricity generation by inhibiting the microbial activity [18]. In addition, alkaline medium increased biosynthesis of riboflavin from Shewanella, which could also enhance bioanode performance [19]. It was important to note here that a rather fast switching speed of voltage output $(\sim 0.5 \mathrm{~h})$ was achieved by controlling the $\mathrm{pH}$ and temperature, benefiting the next generation of bacteria-based computing circuits or sensors [20].

3.2. CVs of Mixed Biofilm as Affected by $\mathrm{pH}$ and Temperature. In addition to the above mentioned reasons, the electrochemical activity of the redox species in the microbial electron transfer chains is also greatly influenced by temperature and $\mathrm{pH}$, further affecting the whole extracellular electron transfer process. Numerous studies claimed that c-type cytochromes (c Cyts) located on the outer membrane of the microbes were the key redox species participating in the extracellular electron transfer [21, 22]. Figure 2 showed the electrochemical properties of the living c Cyts in the mixed-culture biofilm under different temperature and $\mathrm{pH}$ conditions, which have been rarely reported in previous studies. As shown in Figure 2(a), similar to the CV features of a pure Geobacter strain, there were two pairs of distinct redox peaks on the $\mathrm{CV}$ curve for the biofilm in the nonturnover state, with formal potential at $-0.46 \mathrm{~V}$ and $-0.39 \mathrm{~V}$ (versus SCE), respectively, at $30^{\circ} \mathrm{C}$ and $\mathrm{pH}$ 7.0. These two couples of redox peaks might belong to two different outer membrane c-type cytochromes of $\mathrm{OmcB}$ and $\mathrm{OmcZ}$, respectively [21]. However, the redox peaks positively shifted when the temperature went down. The formal potentials were $-0.44 \mathrm{~V}$ and $-0.37 \mathrm{~V}$ (versus $\mathrm{SCE}$ ) at $20^{\circ} \mathrm{C}$ and $-0.42 \mathrm{~V}$ and $-0.35 \mathrm{~V}$, respectively (versus $\mathrm{SCE}$ ), at $10^{\circ} \mathrm{C}$. Moreover, the peak separations increased and the peak currents decreased as the temperature decreased, implying decreases in the electrochemical activities of $\mathrm{c}$ Cyts. As a result, the electrochemical catalytical activity of the anode biofilm dropped accordingly (Figure 2(b)). It is worth mentioning that temperature caused more significant change in the oxidation peak potential than in the reduction peak potential, demonstrating greater influence of temperature on the oxidation process of the c Cyts. Similar changes in the redox potential of $c$ Cyts were also observed when medium $\mathrm{pH}$ was changed. As shown in Figure 2(c), when $\mathrm{pH}$ decreased, the redox potentials positively shifted by ca. $40 \mathrm{mV}$, suggesting that the redox processes of these redox active species were $\mathrm{pH}$-dependent. The peak separations increased and the peak currents decreased as $\mathrm{pH}$ decreased, indicating decrease of the electrochemical activity of the $c$ Cyts and the electrochemical catalytical activity of the anode biofilm (Figure 2(d)).

3.3. UV-Vis Spectroscopy Measurements of In Vivo c Cyts as Affected by $\mathrm{pH}$ and Temperature. The effects of temperature and $\mathrm{pH}$ on in vivo c Cyts were further evidenced by investigating the whole cell using a UV-Vis spectroscopy. Bacteria with outer membrane bonded c-type cytochromes showed distinguished UV-Vis spectra with different redox states [23]. The oxidized c Cyts have a Soret band at $409 \mathrm{~nm}$ and a broad band at $528 \mathrm{~nm}$ (Figure 3). After c Cyts were reduced by sodium dithionite, reduced c Cyts show the Soret, $\beta$, and $\alpha$ bands at 419, 520, and $550 \mathrm{~nm}$, respectively. A similar shift in the Soret absorption band was reported for purified c Cyts [24]. These spectral features are typical of hexacoordinated low-spin hemes and are obviously affected by environmental stimuli. An apparent red shifting of the Soret band and the absence of the peaks at 522 and $552 \mathrm{~nm}$ was observed for the oxidized living c Cyts while the temperature went down (Figure 3(a)). However, no shifting but a decrease in intensity of the absorbance peaks for the reduced c Cyts was observed when temperature decreased (Figure 3(b)). The spectral features also changed when the medium $\mathrm{pH}$ was 


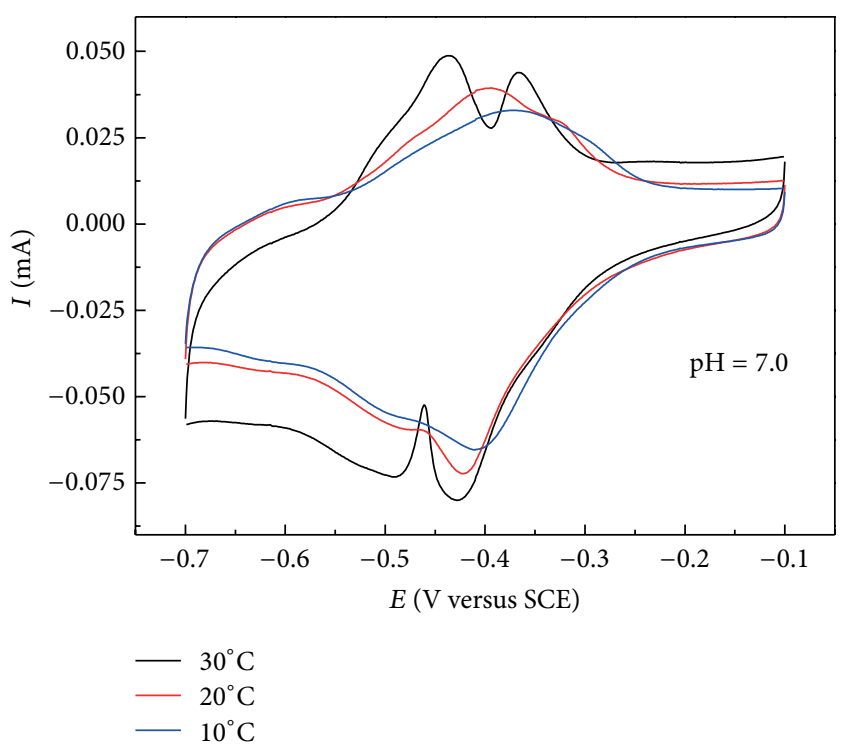

(a)

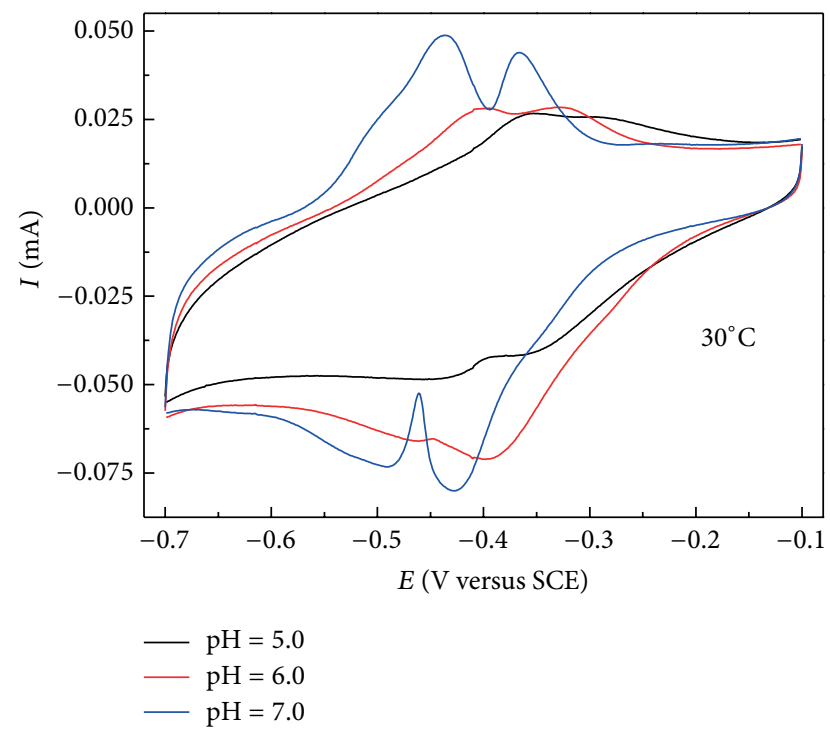

(c)

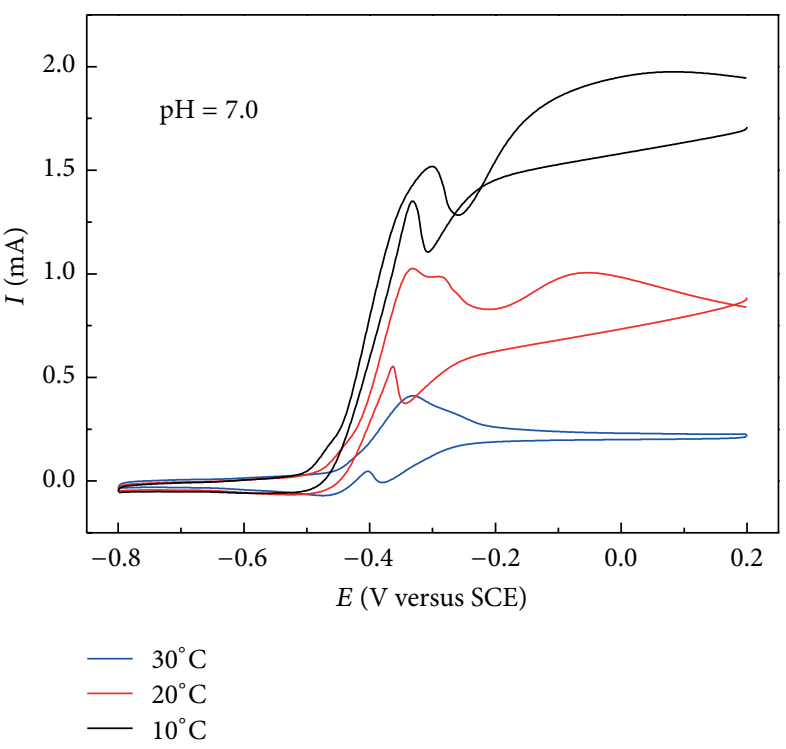

(b)

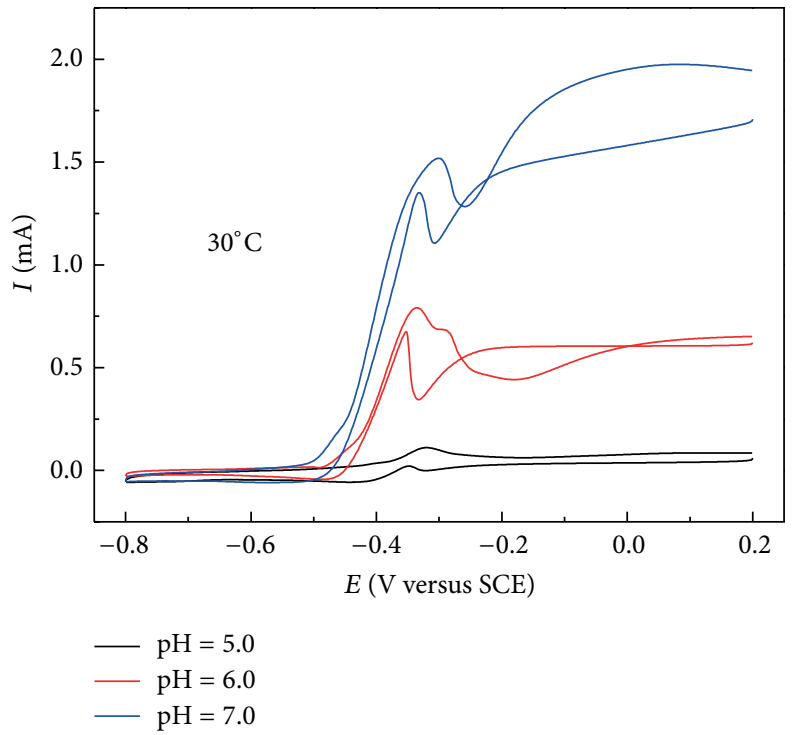

(d)

FIGURE 2: CVs of the anode biofilm under various temperatures by fixing $\mathrm{pH}$ condition under no-turnover state (a) and turnover state (b); CVs of the anode biofilm under various $\mathrm{pH}$ levels by fixing temperature condition under no-turnover state (c) and turnover state (d).

adjusted. The Soret band of the oxidized c Cyts shifted to $393 \mathrm{~nm}$ with a lower intensity (Figure 3(c)). The position and the intensity of the Soret absorption band were related to the conformational state of the heme group in c Cyts and the weakening of the heme crevice [25]. The appearance of the Soret band at $393 \mathrm{~nm}$ demonstrated the formation of a fully high-spin heme complex. No obvious shifts of the Soret band but a weakening in absorption intensity for all the bands were observed when the medium became acid. On the other hand, the blue shifts of the Soret absorption band of both the oxidized and reduced cytochromes were also observed under an alkaline condition. The results suggested that environmental stimuli apparently had an effect on the conformational state of the heme groups in c Cyts and in turn the electrochemical properties of the c Cyts, which provided an opportunity for tuning the extracellular electron transfer of the whole cell.

3.4. The Combined Effect of $\mathrm{pH}$ and Temperature on the Bioelectricity Generation from the MFC. To take advantage of the switchable electrochemical activity of the whole cell by the combined effect of $\mathrm{pH}$ and temperature, we constructed a "smart" MFC. In such a device, bioelectricity generation from the MFC could be controlled by temperature and $\mathrm{pH}$. As shown in Figure 4(a), the highest power output was achieved 


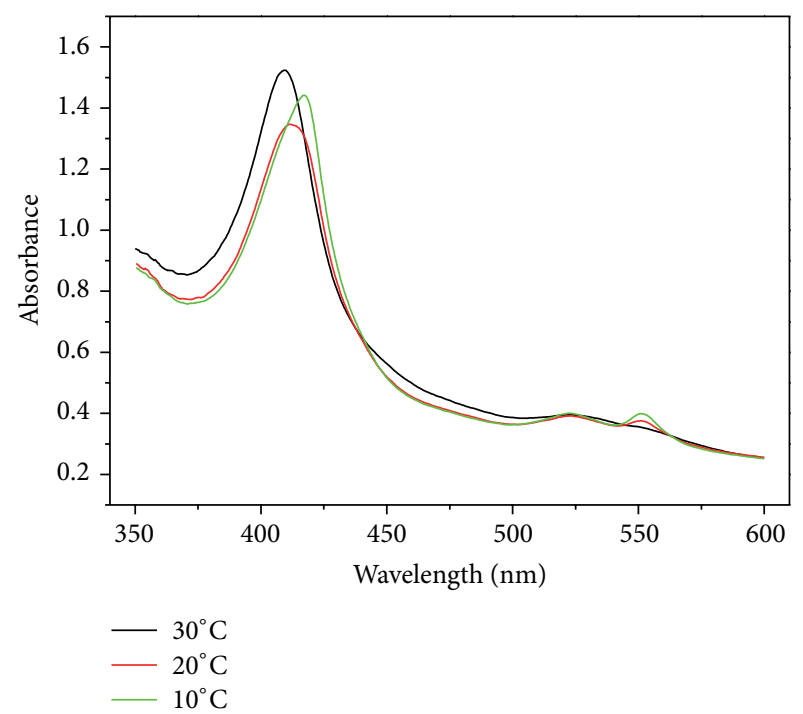

(a)

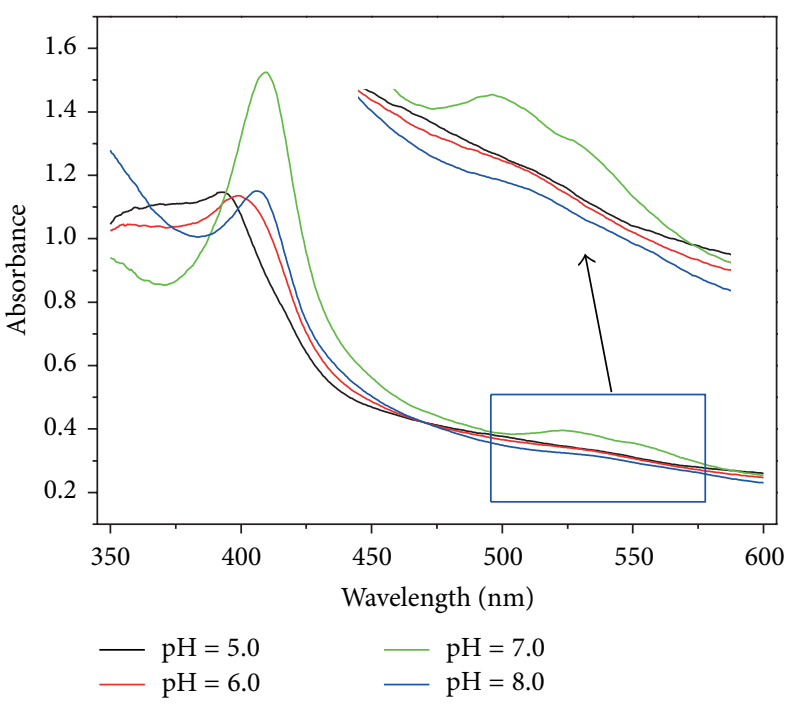

(c)

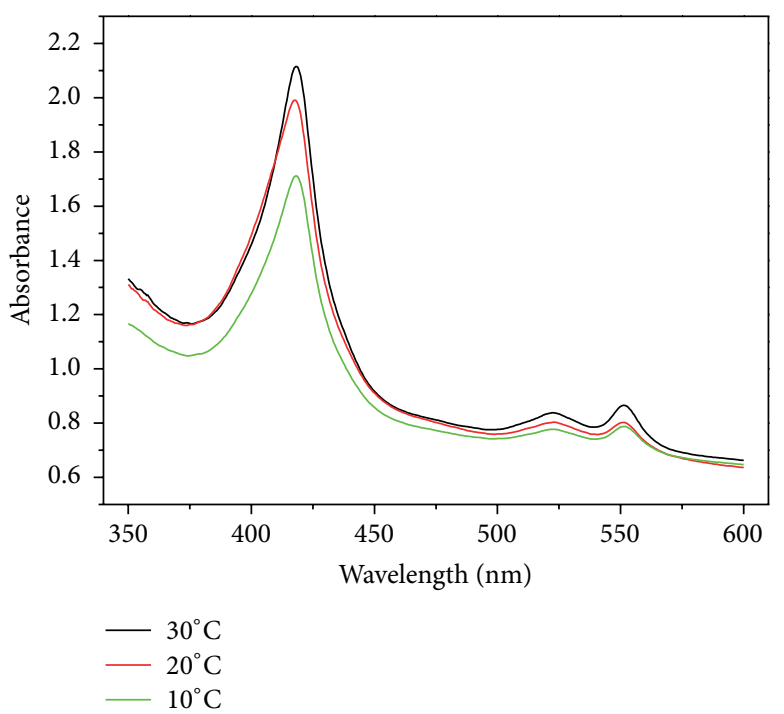

(b)

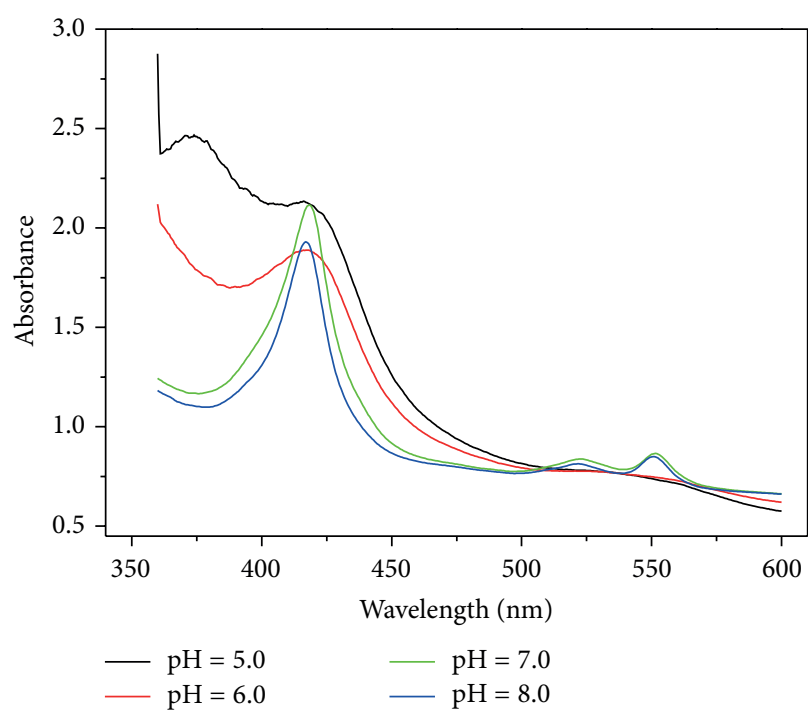

(d)

FIGURE 3: Electronic absorption spectra of G. sulfurreducens under various temperatures at pH 7.0 in oxidized state (a) and reduced state (b); electronic absorption spectra under various $\mathrm{pH}$ values at $30^{\circ} \mathrm{C}$ in oxidized state $(\mathrm{c})$ and reduced state $(\mathrm{d})$.

under the conditions of $30^{\circ} \mathrm{C}$ and $\mathrm{pH} 7.0$, while a very low power output was generated under conditions of lower temperature or $\mathrm{pH}$. Based on this, a Boolean AND logic operation was developed for power generation. In this logic operation, $\mathrm{pH}$ and temperature were designed as input signals (A and B signals, resp.), and the maximum power output was taken as output signal (Figure 4(b)). Conditions of $\mathrm{pH} 7.0$ and $30^{\circ} \mathrm{C}$ were considered as logic input 1 , and conditions of $\mathrm{pH} 5.0$ and $10^{\circ} \mathrm{C}$ were considered as logic input 0 . The input signals were applied in all four combinations $(0,0 ; 0,1$; 1,0; and 1,1) as shown in Figures 4(c) and 4(d). The highest power density for all MFC tests was obtained for input 1,1 $\left(1600 \mathrm{~mW} \mathrm{~m}^{-2}\right)$. In contrast, the power output was at a low level when input was $0,0,0,1$, or 1,0 . The threshold of the Boolean logic AND gate for the MFC was $180 \mathrm{~mW} \mathrm{~m}^{-2}$.

\section{Conclusion}

In this study, the "smart" MFC presented above demonstrated for the first time the possibility to control the power output of an MFC by adjusting environmental conditions according to Boolean logic operations. This provides opportunities for future sensor and bioelectronic devices logically controlled by physiological parameters. "Smart" MFCs can be a promising alternative to enzyme-based biofuel cell systems due to their long-term stability, scalability, and easy handling properties. 


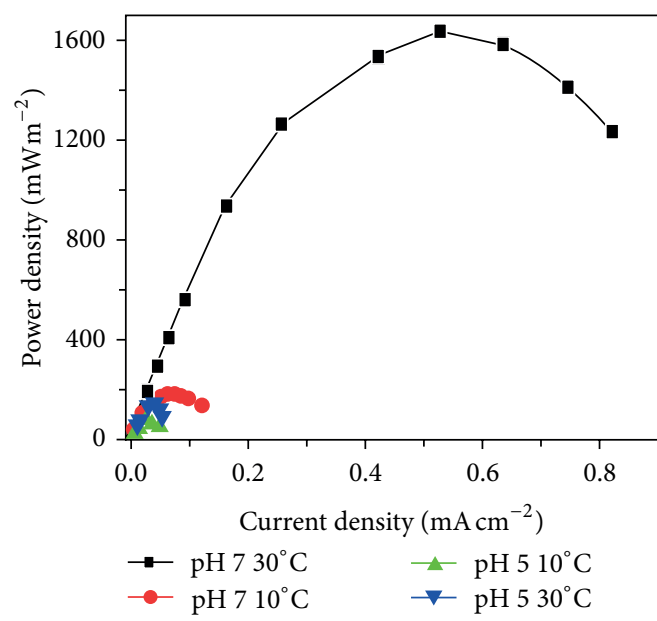

(a)

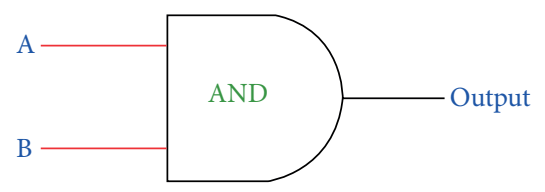

(b)

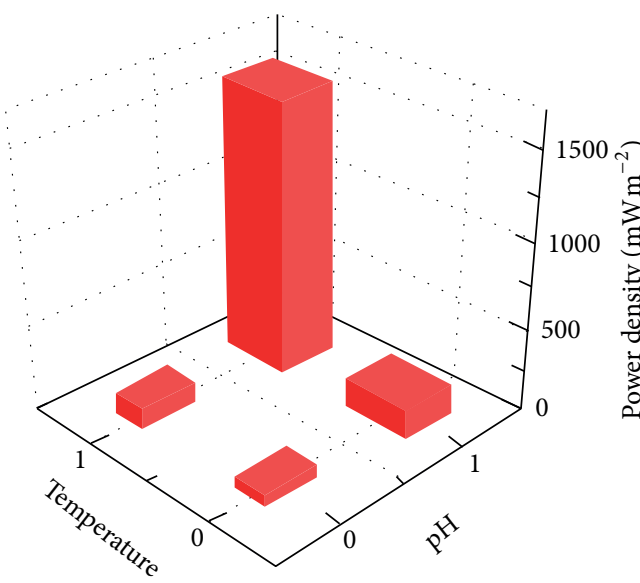

(c)

\begin{tabular}{ccc}
\hline $\begin{array}{c}\text { Input A } \\
(\mathrm{pH})\end{array}$ & $\begin{array}{c}\text { Input } \mathrm{B} \\
\text { (temperature) }\end{array}$ & $\begin{array}{c}\text { Output } \\
\text { (power density) }\end{array}$ \\
\hline $0(5)$ & $0\left(10^{\circ} \mathrm{C}\right)$ & 0 \\
\hline $0(5)$ & $1\left(30^{\circ} \mathrm{C}\right)$ & 0 \\
\hline $1(7)$ & $0\left(10^{\circ} \mathrm{C}\right)$ & 0 \\
\hline $1(7)$ & $1\left(30^{\circ} \mathrm{C}\right)$ & 1 \\
\hline
\end{tabular}

(d)

FIgURE 4: Polarization curves of the MFC under various conditions (a); equivalent circuit of an AND logic gate based on the MFC (b); the maximum power output of the MFC for four different input combinations (c); and truth table for the logically controlled power output (d).

An MFC with switchable and tunable power release might broaden its application in sensor, medical, and environmental fields.

\section{Conflict of Interests}

The authors declared that they have no conflict of interests regarding this work.

\section{Acknowledgments}

This study was supported jointly by the National Natural Science Foundation of China (no. 21277035), the Foundation for Excellent Young Scientist in Guangdong Academy of Sciences (no. rcjj201101), the Agricultural Science and Technology Achievements Transformation Fund Programs of Guangdong Province, China (2012NL040), and Guangzhou Science and Technology Development Foundation, China (2011)2200039).

\section{References}

[1] B. E. Logan, B. Hamelers, R. Rozendal et al., "Microbial fuel cells: methodology and technology," Environmental Science and Technology, vol. 40, no. 17, pp. 5181-5192, 2006.

[2] K. Rabaey and W. Verstraete, "Microbial fuel cells: novel biotechnology for energy generation," Trends in Biotechnology, vol. 23, no. 6, pp. 291-298, 2005.

[3] V. B. Wang, S. L. Chua, B. Cao et al., "Engineering PQS biosynthesis pathway for enhancement of bioelectricity production in Pseudomonas aeruginosa microbial fuel cells," PLOS ONE, vol. 8, no. 5, Article ID e63129, 2013.

[4] L. M. Tender, S. A. Gray, E. Groveman et al., "The first demonstration of a microbial fuel cell as a viable power supply: powering a meteorological buoy," Journal of Power Sources, vol. 179 , no. 2, pp. 571-575, 2008.

[5] F. Zhang, L. Tian, and Z. He, "Powering a wireless temperature sensor using sediment microbial fuel cells with vertical arrangement of electrodes," Journal of Power Sources, vol. 196, no. 22, pp. 9568-9573, 2011. 
[6] C.-P. Siu and M. Chiao, "A microfabricated PDMS microbial fuel cell," Journal of Microelectromechanical Systems, vol. 17, no. 6, pp. 1329-1341, 2008.

[7] E. Katz and M. Pita, "Biofuel cells controlled by logically processed biochemical signals: towards physiologically regulated bioelectronic devices," Chemistry, vol. 15, no. 46, pp. 1255412564, 2009.

[8] E. Katz and I. Willner, "A biofuel cell with electrochemically switchable and tunable power output," Journal of the American Chemical Society, vol. 125, no. 22, pp. 6803-6813, 2003.

[9] L. Amir, T. K. Tam, M. Pita, M. M. Meijler, L. Alfonta, and E. Katz, "Biofuel cell controlled by enzyme logic systems," Journal of the American Chemical Society, vol. 131, no. 2, pp. 826-832, 2009.

[10] K. T. Tsz, G. Strack, M. Pita, and E. Katz, "Biofuel cell logically controlled by antigen-antibody recognition: towards immuneregulated bioelectronic devices," Journal of the American Chemical Society, vol. 131, no. 33, pp. 11670-11671, 2009.

[11] M. Zhou, Y. Du, C. Chen et al., "Aptamer-controlled biofuel cells in logic systems and used as self-powered and intelligent logic aptasensors," Journal of the American Chemical Society, vol. 132, no. 7, pp. 2172-2174, 2010.

[12] Y. Yuan, S. Zhou, J. Zhang, L. Zhuang, G. Yang, and S. Kim, "Multiple logic gates based on reversible electron transfer of self-organized bacterial biofilm," Electrochemistry Communications, vol. 18, no. 1, pp. 62-65, 2012.

[13] Z. Li, M. A. Rosenbaum, A. Venkataraman, T. K. Tam, E. Katz, and L. T. Angenent, "Bacteria-based and logic gate: a decisionmaking and self-powered biosensor," Chemical Communications, vol. 47, no. 11, pp. 3060-3062, 2011.

[14] Y. Yuan, S. Zhou, N. Xu, and L. Zhuang, "Electrochemical characterization of anodic biofilms enriched with glucose and acetate in single-chamber microbial fuel cells," Colloids and Surfaces B, vol. 82, no. 2, pp. 641-646, 2011.

[15] Y. Liu, H. Kim, R. Franklin, and D. R. Bond, "Gold line array electrodes increase substrate affinity and current density ofelectricity-producing G. sulfurreducens biofilms," Energy and Environmental Science, vol. 3, no. 11, pp. 1782-1788, 2010.

[16] A. Esteve-Núñez, J. Sosnik, P. Visconti, and D. R. Lovley, "Fluorescent properties of c-type cytochromes reveal their potential role as an extracytoplasmic electron sink in Geobacter sulfurreducens," Environmental Microbiology, vol. 10, no. 2, pp. 497-505, 2008.

[17] A. Gonzalez del Campo, J. Lobato, P. Cañizares, M. A. Rodrigo, and F. J. Fernandez Morales, "Short-term effects of temperature and COD in a microbial fuel cell," Applied Energy, vol. 101, pp. 213-217, 2013.

[18] S. Jung, M. M. Mench, and J. M. Regan, "Impedance characteristics and polarization behavior of a microbial fuel cell in response to short-term changes in medium $\mathrm{pH}$," Environmental Science and Technology, vol. 45, no. 20, pp. 9069-9074, 2011.

[19] Y. Yong, Z. Cai, Y. Yu et al., "Increase of riboflavin biosynthesis underlies enhancement of extracellular electron transfer of Shewanella in alkaline microbial fuel cells," Bioresource Technology, vol. 130, pp. 763-768, 2013.

[20] M. A. Teravest, Z. Li, and L. T. Angenent, "Bacteria-based biocomputing with cellular computing circuits to sense, decide, signal, and act," Energy and Environmental Science, vol. 4, no. 12, pp. 4907-4916, 2011.

[21] K. Fricke, F. Harnisch, and U. Schröder, "On the use of cyclic voltammetry for the study of anodic electron transfer in microbial fuel cells," Energy and Environmental Science, vol. 1, no. 1, pp. 144-147, 2008.

[22] Y. Liu, F. Harnisch, K. Fricke, R. Sietmann, and U. Schröder, "Improvement of the anodic bioelectrocatalytic activity of mixed culture biofilms by a simple consecutive electrochemical selection procedure," Biosensors and Bioelectronics, vol. 24, no. 4, pp. 1006-1011, 2008.

[23] B. Cao, B. Ahmed, D. W. Kennedy et al., "Contribution of extracellular polymeric substances from Shewanella sp. HRCR1 biofilms to U(VI) immobilization," Environmental Science and Technology, vol. 45, no. 13, pp. 5483-5490, 2011.

[24] R. Nakamura, K. Ishii, and K. Hashimoto, "Electronic absorption spectra and redox properties of $\mathrm{C}$ type cytochromes in living microbes," Angewandte Chemie, vol. 48, no. 9, pp. 16061608, 2009.

[25] M. Collinson and E. F. Bowden, "UV-visible spectroscopy of adsorbed cytochrome c on tin oxide electrodes," Analytical Chemistry, vol. 64, no. 13, pp. 1470-1476, 1992. 


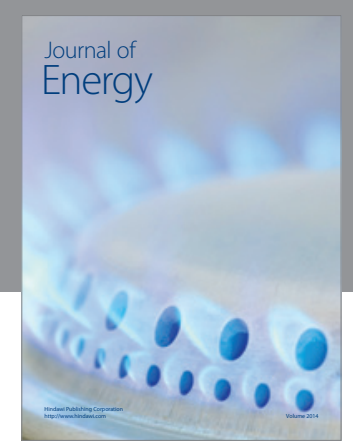

Journal of

Industrial Engineering
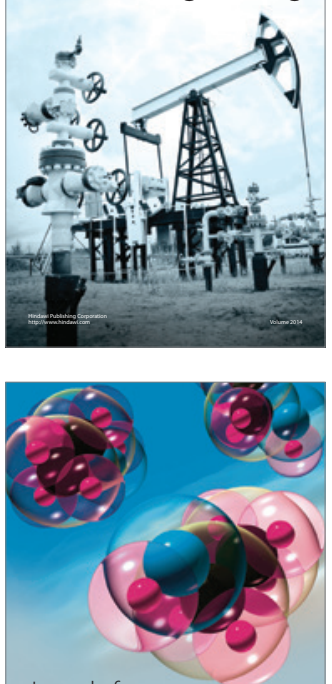

Fuels
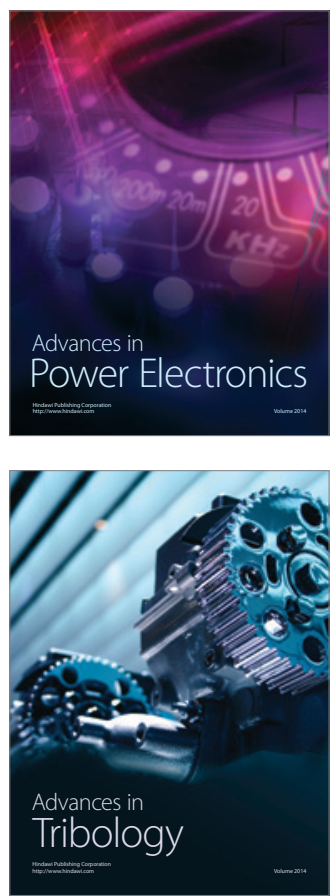

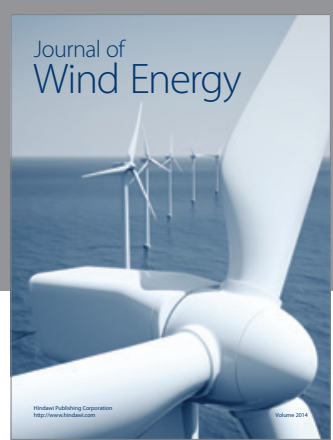

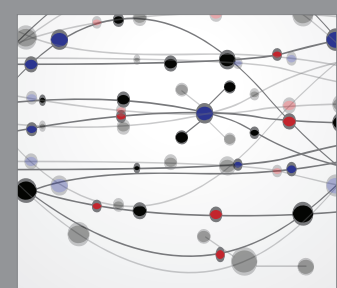

The Scientific World Journal

Submit your manuscripts at http://www.hindawi.com

Journal of

Structures
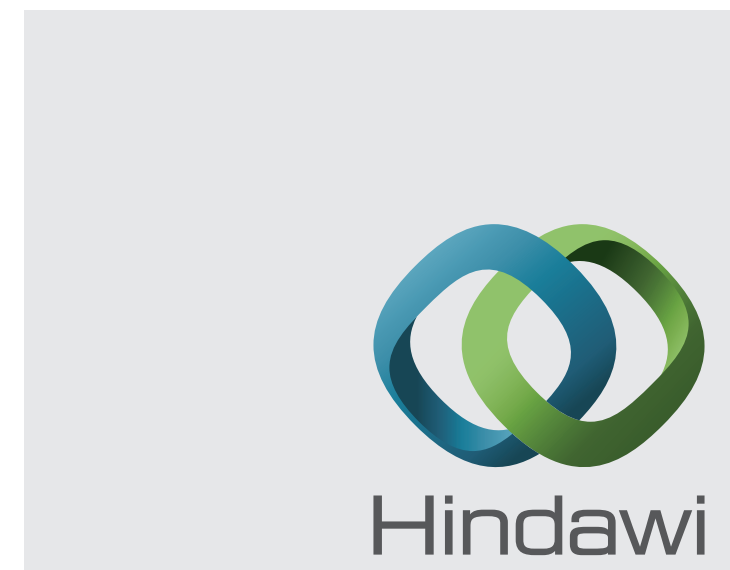

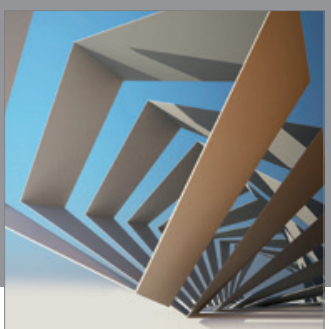

Rotating

Machinery
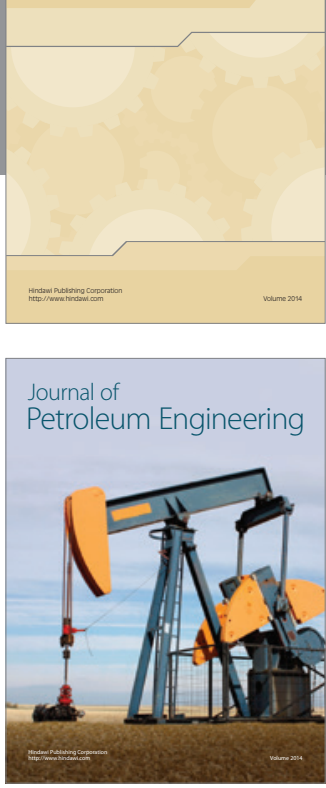

Journal of

Solar Energy
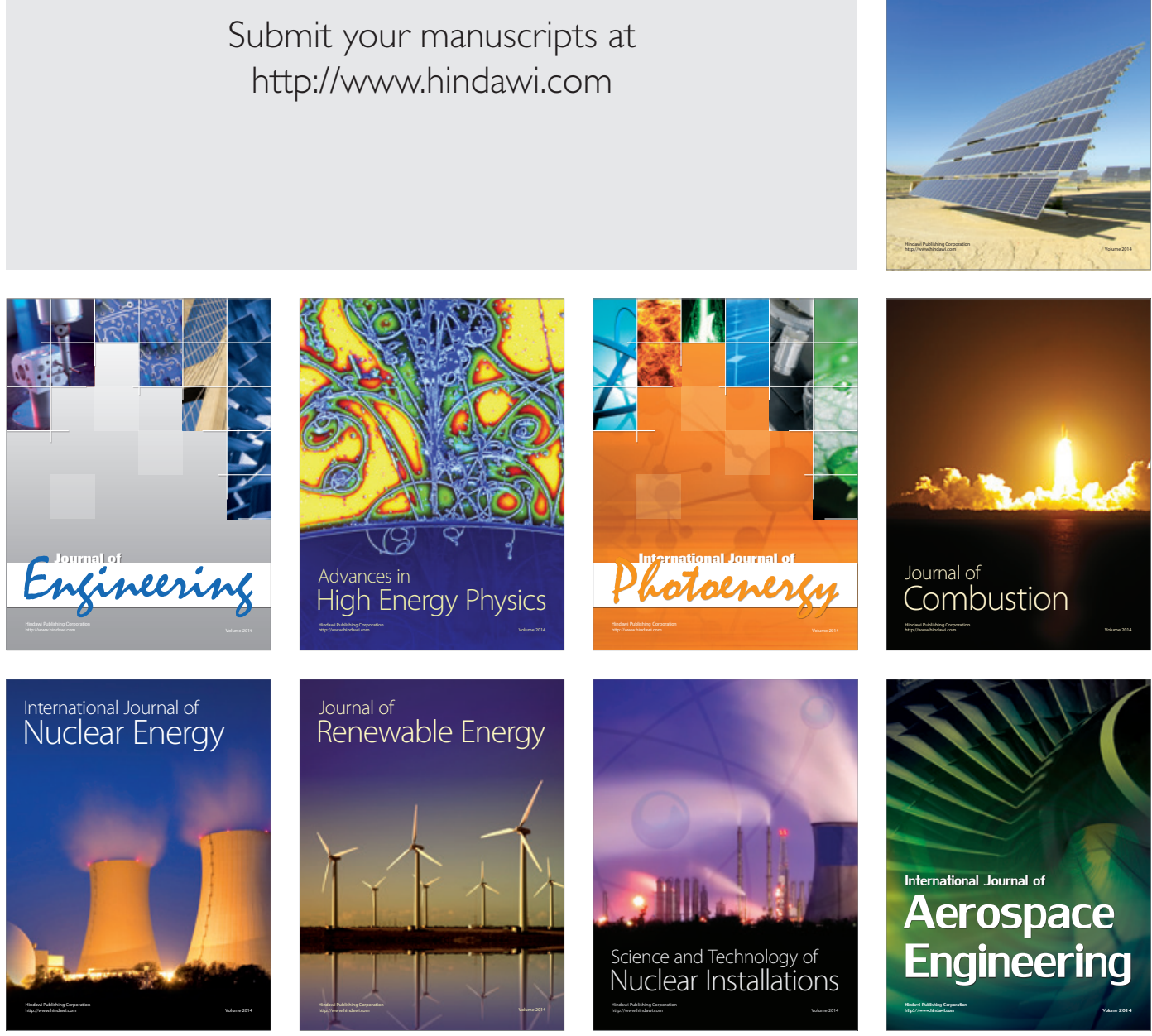